\title{
ApLICAÇÃo do MÉTOdo dA CARGA MÁXIMA TOTAL DIÁRIA (CMTD) PARA A AMÔNIA NO RIO ATIBAIA, REGIÃO DE Campinas/Paulínia - SP
}

\author{
APPLICATION OF AMMONIA TOTAL MAXIMUM DAILY LOAD (TMDL) TO ATIBAIA \\ river, Campinas/Paulínia region - São Paulo state
}

GILBERTO SILVÉRIO DA SILVA

Químico. Doutor em Ciências pela Unicamp. Professor da UTFPR, campus Medianeira

\section{WILSON F. JARDIM}

Químico. Ph. D. em Ciências Ambientais pela Universidade de Liverpool, Inglaterra. Professor Titular do Instituto de Química, Unicamp - Campinas

Recebido: 06/03/06 Aceito: 05/03/07

\section{RESUMO}

Neste estudo foram avaliadas a capacidade de suporte e o estado de degradação do Rio Atibaia, considerando a ameaça para a vida aquática pela presença da Amônia, a qual representa um dos principais riscos às comunidades aquáticas no Rio Atibaia. Com este objetivo foi aplicado o método da Carga Máxima Total Diária (CMTD), da Agência de Proteção Ambiental dos Estados Unidos (EPA). Os resultados revelaram que as cargas de Amônia aumentavam progressivamente ao longo do Rio Atibaia, principalmente devido às fontes pontuais. As cargas de Amônia diárias assumiram valores de 30 a $5000 \mathrm{~kg} \mathrm{NH}$. A capacidade de suporte das águas Rio Atibaia, para proteger a vida aquática contra os efeitos tóxicos da Amônia, tem sido violadas em trechos próximos à sua foz. A degradação dessas águas foi mais intensa na estação seca. Este trabalho mostrou que o esgoto doméstico não-tratado de uma população aproximada de 250 mil habitantes da cidade de Campinas, via Ribeirão Anhumas, é a principal fonte de Amônia na bacia do Rio Atibaia, apesar do grande número de indústrias ali presentes.

PALAVRAS-CHAVE: Rio Atibaia, qualidade das águas, fontes pontuais e difusas, Amônia, CMTD e TMDL.

\begin{abstract}
This study evaluated the tolerance capacity and the impairment state of the Atibaia River, considering the threat to aquatic life by the presence of Ammonia, which represents one of the main risks to the aquatic communities in the Atibaia River. With this aim, the method Total Maximum Daily Load (TMDL), from the United States Environmental Protection Agency (EPA), was applied. The results revealed that the Ammonia loads increased progressively through the Atibaia River, especially due to the point sources. The daily Ammonia loads assumed values that ranged from 30 to $5000 \mathrm{~kg} \mathrm{NH3}$. The tolerance capacity of the waters of the Atibaia River, to protect aquatic life against the toxic effects of the Ammonia, has been violated in reaches near its mouth. The impairment of these waters was more intense during the dry season. This study showed that the domestic sewer not treated of an approximate population of 250 thousand inhabitants in the city of Campinas is the main source of Ammonia in the Atibaia River Basin, despite the number of industries present there.
\end{abstract}

KEYWORDS: Atibaia River, water quality, point and nonpoint sources, ammonia, CMTD and TMDL.

\section{INTRODUÇÃO}

Na gestão dos recursos hídricos, a preocupação com a qualidade das águas para seus usos múltiplos demanda um constante monitoramento das variáveis bióticas e abióticas. Em se tratando das variáveis físico-químicas, os resultados desse monitoramento são comumente comparados com os padróes de qualidade definidos na Resolução Federal Conama 357/05, que trata da qualidade das águas superficiais.

Outra dimensão da gestão da qualidade das águas é o controle das fontes emissoras de poluentes, controle esse comum para fontes pontuais urbanas como esgoto doméstico e efluentes industriais, e mais raro quando se trata de fontes difusas. Determinados padrôes de emissão para fontes pontuais são tratados na referida Resolução. Esses dois aspectos do controle da qualidade das águas, monitoramento das variáveis bióticas e abióticas e controle das emissões de poluentes, devem se relacionar de modo a garantir que a capacidade de suporte do corpo de água não seja violada. Entende-se a capacidade de suporte de um corpo de água como sendo o valor máximo de determinado poluente que esse corpo hídrico pode manter em suas águas sem que as suas funções ecológicas sejam comprometidas (Silva, 2004; Silva e Jardim, 2006; MMA, 1995). Essas funções ecológicas significam as capacidades de manter a vida aquática, manter a recreação de contato primário, fornecer água para abastecimento público, entre outras.

A Resolução Federal Conama 357/05 em seu artigo 26 parágrafo primeiro estabelece: "No caso de empreendimento de significativo impacto, o órgão ambiental competente exigirá... 
a apresentação de estudo de capacidade de suporte de carga do corpo de água receptor". Portanto, o referido artigo traz à tona o conceito de capacidade de suporte e submetem, desse modo, os padrōes de emissão de poluentes à manutenção dessa capacidade de suporte. $\mathrm{O}$ texto traz ainda em seu artigo 28 um reforço a essa diretiva: "Os efluentes não poderão conferir ao corpo de água características em desacordo com as metas... do seu enquadramento".

Nos Estados Unidos, por exigência de lei Federal (CWA, 1972), os estados devem informar à Agência de Proteção Ambiental (EPA) desse país aqueles corpos de água que estão em desacordo com os padrôes definidos em seu enquadramento e devem necessariamente estabelecer um plano de controle e recuperação desses corpos de água. A metodologia seguida é a "Total Maximum Daily Loads - TMDL" (EPA, 1999a), denominada neste estudo de método da Carga Máxima Total Diária - CMTD (Silva, 2004). A metodologia da CMTD é obrigatória para esses casos, sendo que os trechos dos corpos de água degradados passam a constar de uma lista nacional. $\mathrm{O}$ método da CMTD é basicamente um instrumento de gestão ambiental baseado na qualidade das águas, capaz de acionar e canalizar açóes em uma bacia hidrográfica de modo a levar ou manter um corpo de água dentro dos padrões estabelecidos para a sua classe.

\section{O método da Carga Máxima Total Diária (CMTD)}

A equação básica que define o cálculo da CMTD é:

$\mathrm{CMTD}=\mathrm{CP}+\mathrm{CD}+\mathrm{C}$

onde, a CMTD representa um valorlimite e refere-se à carga, em kg/dia, de um poluente que pode ser lançada em um corpo de água sem que os seus padrōes de qualidade sejam violados. O valor da CMTD é uma expressão numérica da capacidade de suporte de um corpo de água e deve orientar todas as ações de controle da poluiçãao na bacia hidrográfica. A CMTD é estimada partindo-se de uma concentração-limite do poluente em estudo e da vazão do corpo de água. As cargas pontuais (CP) e as cargas difusas (CD) representam a outra dimensão do controle ambiental: as fontes emissoras. A soma das CP e das CD representam o total de poluente emitido e que chega efetivamente ao corpo receptor. O termo C na Equação (1) é um fator de segurança quanto às incertezas nas estimativas das cargas pontuais e difusas, garantindo assim que o valor-limite não seja violado.

Para a estimativa da CMTD é necessário escolher a variável ambiental que será objeto de estudo e o seu respectivo valor numérico que garantirá a qualidade desejada da água. Esse valor numérico pode ser a concentraçãolimite do poluente, que passa a ser o valor-alvo da CMTD, com sua concentração desempenhando a função de indicador de desempenho da CMTD. Uma vez definida a condição anterior, é necessário medir a vazão, de modo que seja possível estimar a CMTD. Neste estudo, foi escolhida a concentração de Amônia como indicador de qualidade, cujos valores-alvo foram os estabelecidos pela EPA (EPA, 1999b) e adotados parcialmente pela Resolução Conama 357/05.

O passo seguinte na aplicação do método da CMTD é estimar a carga real de Amônia que é lançada diariamente no Rio Atibaia. Para tanto, segue-se o mesmo procedimento anterior, utilizando dados de concentração de Amônia e vazão, mas agora utilizando o valor da concentração medida da Amônia no corpo de água, em lugar dos valores-alvo de concentração de Amônia segundo o critério da EPA/Conama. Essa carga passa a ser denominada de carga total diária (CTD). A CTD pode, portanto, ser menor, igual ou maior que a CMTD.

A próxima etapa consiste em caracterizar qualitativamente as fontes emissoras. Essa caracterização qualitativa implica em classificá-las em perene ou sazonal, em doméstica ou industrial, em pontual ou difusa e em agropecuária ou urbana, além de sua localização geográfica. Segue-se, por sua vez, a caracterização quantitativa das fontes, que consiste em desagregar a CTD estimada em seus respectivos componentes. Essa distribuição de cargas deve tanto quanto possível dar conta da relação quantidade emitida e quantidade que chega ao corpo receptor. Com esse objetivo, modelos matemáticos que consideram fatores como degradação química, degradação biológica, geração biológica e perdas atmosféricas podem ser utilizados.

A CMTD pode ser aplicada em corpos de água que apresentam uma violação de seus critérios de qualidade, ou simplesmente para adquirir um conhecimento estratégico na gestão hídrica de determinada bacia hidrográfica. Avançando para o passo seguinte na aplicação da CMTD, numa situação em que a capacidade de suporte do corpo de água esteja violada, é necessário estabelecer metas de redução da CTD que chega ao corpo receptor, pressupondo, é claro, que as fontes pontuais estejam obedecendo aos valores-limites de emissão e que as atividades antrópicas rurais estejam utilizando as melhores tecnologias disponíveis. Essa alocação de cargas a serem reduzidas exige e permite uma visão sistêmica sobre a dinâmica de emissão de determinado poluente numa bacia hidrográfica, suscitando um maior relacionamento entre mecanismos como monitoramento ambiental, licenciamento ambiental e investimentos na bacia hidrográfica. Essa necessidade de redução de carga faz surgir também um terreno gerencial propício ao mecanismo de cotas de emissão. No caso em que um novo empreendimento poluidor, apesar de emitir dentro dos padróes previstos em lei, comprometer o valor da CMTD, esse empreendimento poderá investir na minimização da CTD, na construção de uma ETE, por exemplo, e assim adquirir uma cota de emissão.

\section{A ecotoxicologia da Amônia}

Amônia é um termo geral para designar as espécies Amônia e Amônio. A espécie Amônia $\left(\mathrm{NH}_{3}\right)$ também é denominada Amônia não-ionizada ou Amônia molecular. Já o íon amônio $\left(\mathrm{NH}_{4}^{+}\right)$, por sua vez, recebe também a denominação de Amônia ionizada. Essas espécies da Amônia se relacionam em sistemas aquosos pela seguinte expressão de equilíbrio:

$\mathrm{NH}_{3}+\mathrm{H}^{+} \leftrightarrow \mathrm{NH}_{4}^{+}$

Portanto, a distribuição das espécies da Amônia em meio aquoso vai depender da constante de equilíbrio $(\mathrm{K})$, onde o logaritmo do seu inverso é denominado $\mathrm{pK}$, que depende da temperatura ( $\mathrm{T}$, em graus Celsius) e do $\mathrm{pH}$. As Equações (3) a (5) permitem calcular a fração de cada espécie química da Amônia, $\mathrm{f}_{\mathrm{NH}_{3}}$ e $\mathrm{f}_{\mathrm{NH}_{4}^{+}}$, em um sistema aquoso. Neste texto, o termo Amônia ou Amônia total se refere às duas espécies. Para se referir a uma espécie em particular será utilizado o termo Amônia não-ionizada para 
$\mathrm{NH}_{3}$ e Amônia ionizada para $\mathrm{NH}_{4}^{+}$ (EPA, 1999b).

$\mathrm{pK}=0,09018+\frac{2729,92}{(273,2+\mathrm{T})}$

$\mathrm{f}_{\mathrm{NH}_{3}}=\frac{1}{\left(1+10^{(\mathrm{pK}-\mathrm{pH})}\right)}$

$\mathrm{f}_{\mathrm{NH}_{4}^{+}}=\frac{1}{\left(1+10^{(\mathrm{pH}-\mathrm{pK})}\right)}$

A Amônia não-ionizada é aproximadamente cem vezes mais tóxica às espécies aquáticas que a forma ionizada. Essa maior toxicidade certamente se deve a capacidade de difusão da Amônia não-ionizada pela membrana epitelial das espécies aquáticas, dificultando, por exemplo, mecanismos naturais de eliminação dessa substância desses organismos (Canadian, 2000). A maior toxicidade dessa espécie fez com que inúmeros padrôes ecotoxicológicos $\mathrm{da}$ Amônia fossem expressos como Amônia não-ionizada. A Resolução Federal CONAMA 20/86, substituída pela $357 / 05$, trazia para corpos de água classes 1 e 2 o valor de $0,02 \mathrm{mg} / \mathrm{l}$ de Amônia não-ionizada. $\mathrm{Na}$ nova legislação CONAMA, os padrões para Amônia passaram a ser expressos como Amônia total (mais especificamente como nitrogênio amoniacal total) em função do pH. Essa forma de expressar a ecotoxicidade da Amônia, considerando o $\mathrm{pH}$, segue a proposta da EPA que expressa a toxicidade crônica da Amônia como Amônia total em função do $\mathrm{pH}$, da temperatura e da presença ou não de espécies de peixes em seus estágios iniciais de vida, além de considerar as variáveis tempo e freqüência. De fato, a EPA utiliza o trinômio concentração-tempo-frequência para definir seus critérios de ecotoxicidade (EPA, 1999b). A Tabela 1 traz alguns valores de ecotoxicidade crônica da Amônia. Um aspecto interessante mostrado na Tabela 1 é a considerável redução da concentração da Amônia total frente ao aumento da temperatura. Esse comportamento também é observado com o aumento do $\mathrm{pH}$. Em resumo, corpos de água com temperaturas e $\mathrm{pH}$ mais elevados tornam-se ecossistemas mais frágeis à presença da Amônia.

A ecotoxicidade da Amônia é um campo aberto. A própria EPA está em vias de reformular seus critérios sobre os efeitos tóxicos dessa substância para as comunidades aquáticas (EPA, 2005). Estudos recentes têm mostrado que algumas espécies bivalves apresentam uma sensibilidade à Amônia maior que as observadas nos estudos que fundamentaram o corrente critério. No Brasil, estudos com nosso ecossistema, considerando as espécies nativas e as características físico-químicas, poderiam auxiliar na definição desses valores ecotoxicológicos de um modo mais apropriado.

\section{PARTE EXPERIMENTAL}

\section{A bacia do Rio Atibaia}

O Rio Atibaia, classe 2 da Resolução Federal CONAMA 357/05, nasce na cidade de Atibaia, Estado de São Paulo, oriundo dos rios Atibainha e Cachoeira. Esses dois rios são represados, juntamente com o Rio Jaguari, para, através do sistema Cantareira, fornecer água para a região metropolitana de São Paulo (RMSP), que recebe $33 \mathrm{~m}^{3} / \mathrm{s}$ revertidos da bacia do Rio Atibaia para a bacia do Alto Tietê. Essa reversão diminui a vazão potencial no Rio Atibaia, exigindo de seus gestores um controle eficiente da quantidade e qualidade das águas desse recurso hídrico.

A bacia do Rio Atibaia, compreendendo a região de Campinas/Paulínia, teve um crescimento populacional expressivo nesses últimos trinta anos, na verdade uma expansão da RMSP rumo ao sul do estado de Minas Gerais. Junto com essa expansão populacional, houve um significativo aumento da demanda de água para consumo humano, irrigação, uso industrial e como água de diluição de efluentes industriais e domésticos. A bacia do Rio Atibaia, apesar do grande desenvolvimento econômico, apresenta baixíssimos índices de tratamento de esgoto doméstico. Esse cenário a coloca como uma das bacias hidrográficas mais críticas no país. Para ilustrar esse fato, vale destacar as constantes falta de água para abastecimento público na cidade de Campinas no período de estiagem ou a situação da represa de Americana, completamente eutrofizada (Relatório, 2000).

\section{Os pontos de coleta ao longo do Rio Atibaia}

Os pontos de coleta utilizados neste estudo se distribuem ao logo do Rio Atibaia e são os mesmos utilizados pela CETESB em seus relatórios de qualidade das águas interiores do Estado de São Paulo (CETESB, 2000a). $\mathrm{O}$ ponto P.1 se localiza na estação de captação de água da cidade de Atibaia, com o código CETESB ATIB02010.
O ponto P.2, código ATIB02065, refere-se a captação de água da cidade de Campinas, logo após a afluência do Ribeirão Pinheiros, que recebe esgoto não-tratado das cidades de Valinhos e Vinhedos, considerando a situação existente na data em que as coletas foram feitas. Finalmente o ponto P.3, código ATIB02605, próximo à foz do Rio Atibaia, após a afluência do Ribeirão Anhumas, passando por denso parque industrial dos municípios de Campinas e Paulínia. O Ribeirão Anhumas recebe o esgoto doméstico não-tratado de uma população aproximada de 250 mil habitantes da cidade de Campinas. A Figura 1 mostra os três pontos de monitoramento.

As coletas de águas no Rio Atibaia ocorrem nos períodos de seca e chuvas. A bacia do Rio Atibaia apresenta períodos de precipitações pluviométricas bem definidos. No mês de julho, por exemplo, foram observadas precipitaçôes com média mensal de $25 \mathrm{~mm}$, enquanto para o mês de janeiro, por sua vez, foram observadas precipitações pluviométricas cujas médias mensais se aproximaram de $250 \mathrm{~mm}$. A Figura 2 mostra a sazonalidade das precipitações na bacia do Rio Atibaia. Essa sazonalidade das precipitações se reflete nas vazões do Rio Atibaia, que assumem valores que podem variar, por exemplo, de $7 \mathrm{~m}^{3} / \mathrm{s}$ no mês de julho a $70 \mathrm{~m}^{3}$ no mês de março (CTH-USP, 2001).

A Tabela 2 mostra as datas das coletas de água no Rio Atibaia. Foram realizados monitoramentos pontuais e monitoramentos de $24 \mathrm{~h}$ com intervalos de amostragem de 2 h (Silva, 2004). As variáveis ambientais medidas foram $\mathrm{pH}$, temperatura e concentração de Amônia. Com exceção da Amônia, todas as variáveis foram determinadas no local da coleta. A determinação da Amônia foi realizada em laboratório por análise em injeção em fluxo (FIA) (Faria et al, 1991). Os dados de vazão do Rio Atibaia foram obtidos junto ao Centro de Tecnologia Hidráulica da USP.

\section{Os métodos de estimativa de cargas}

Para a efetiva implantação do método da CMTD é necessário um conhecimento qualitativo e quantitativo das fontes emissoras. $\mathrm{O}$ estudo qualitativo das fontes emissoras de Amônia foi realizado por Silva (2004), cujos resultados classificam as fontes de Amônia na bacia 
Tabela I - Valores de ecotoxicidade crônica da Amônia em função do $\mathrm{pH}$ e da temperatura'

\begin{tabular}{cccccccccccc}
\hline \multicolumn{10}{c}{} & \multicolumn{10}{c}{ Temperatura, $^{\circ} \mathrm{C}$} \\
$\mathrm{pH}$ & 0 & 14 & 16 & 18 & 20 & 22 & 24 & 26 & 28 & 30 \\
\hline 6,5 & 6,67 & 6,67 & 6,06 & 5,33 & 4,68 & 4,12 & 3,62 & 3,18 & 2,80 & 2,46 \\
7,0 & 5,91 & 5,91 & 5,37 & 4,72 & 4,15 & 3,65 & 3,21 & 2,82 & 2,48 & 2,18 \\
9,0 & 0,486 & 0,486 & 0,442 & 0,389 & 0,342 & 0,300 & 0,264 & 0,232 & 0,204 & 0,179 \\
\hline
\end{tabular}
em EPA, $1999 \mathrm{~b}$

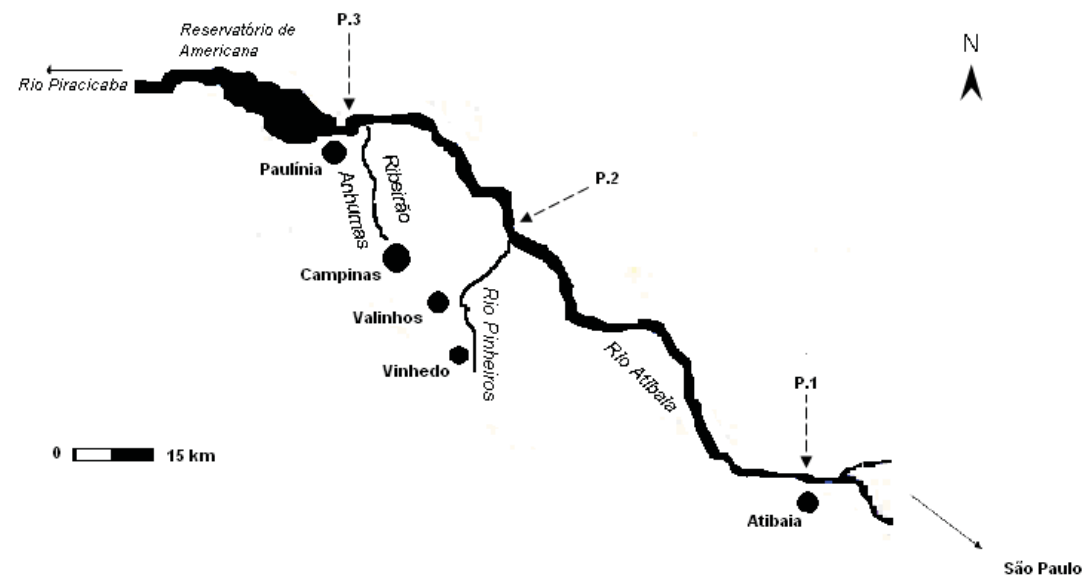

Figura I - Pontos de coleta ao longo do Rio Atibaia. Ponto P. I, na captação de água da cidade de Atibaia. Ponto P.2, na captação de água da cidade de Campinas, após a afluência do Ribeirão Pinheiros. Ponto P.3, após a afluência do Ribeirão Anhumas, próximo à foz do Rio Atibaia

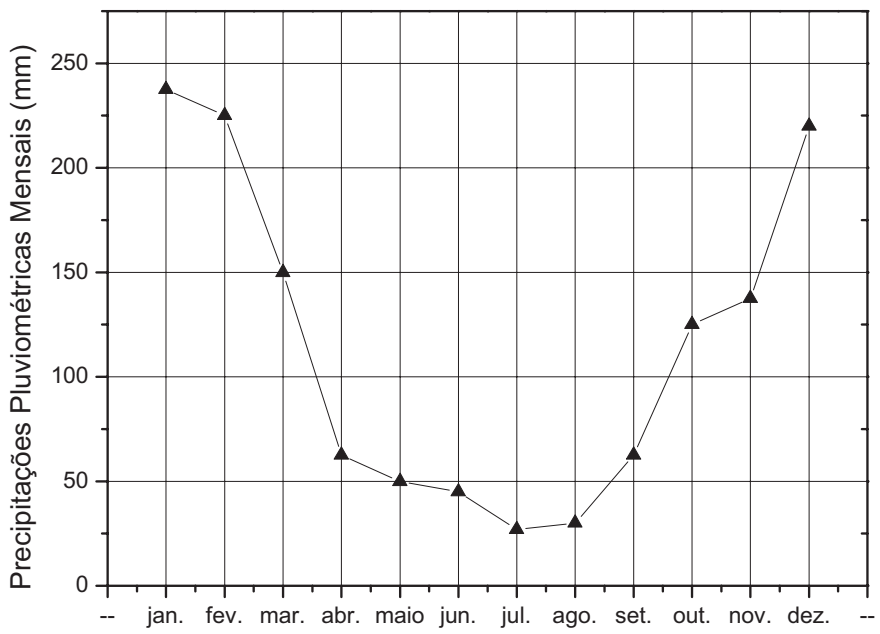

Fonte: Projeto Watershed Management 2000. Brasil.

Figura 2 - Sazonalidade das precipitações mensais na bacia do Rio Atibaia (194 I-1970) 
Tabela 2 - Data das coletas de água no Rio Atibaia

\begin{tabular}{cccc}
\hline $\begin{array}{c}\text { Tipo de } \\
\text { monitoramento }\end{array}$ & $\begin{array}{c}\text { Pontos } \\
\text { de coleta }\end{array}$ & Período de seca - 2001 & Período de chuvas - 2002 \\
\hline Pontual & P.1, P.2 e & 20 de julho & 10 de janeiro(c) e \\
& P.3 & & 01 de abril(c) \\
Perfil 24h & P.1 & 24 e 25 de setembro & 18 e 19 de março(c) \\
& P.2 & 17 e 18 de setembro(c) & 11 e 12 de março \\
& P.3 & 10 e 11 de setembro & 25 e 26 de fevereiro(c)
\end{tabular}

(c) indica que houve a presença de chuvas no decorrer da amostragem ou imediatamente antes da coleta das águas. Os termos período de seca e período de chuvas se devem mais ao perfil de precipitação pluviométrica que propriamente a existência ou não de um evento pluviométrico no momento da coleta.

do Rio Atibaia como predominantemente de origem doméstica, portanto, pontuais, urbanas e perenes ao longo do ano. Geograficamente, essas fontes se localizam nos grandes centros urbanos, como na cidade de Campinas. Deste modo, a presença pouca significativa de fontes difusas de Amônia leva o termo CD na Equação (1) a assumir, por simplificação, o valor zero nesta bacia. Neste trabalho não foi feita a estimativa do termo $\mathrm{C}$ da equação (1). Para caracterizar quantitativamente o termo restante da Equação (1), carga pontual - CP, foram utilizados os seguintes métodos:

Método $\mathrm{n}^{\mathrm{o}}$ 1: aplicado para se estimar a carga de Amônia que aporta no Rio Atibaia num determinado dia - CTD. Para estimar essa carga são necessárias a concentração medida da Amônia e a vazão do Rio Atibaia. Por exemplo: para uma vazão do Rio Atibaia de $7,43 \mathrm{~m}^{3} / \mathrm{s}$ e uma concentração de Amônia de 4,77 mg/l, a CTD é de $3062,9 \mathrm{~kg} /$ dia de Amônia.

Método $\mathrm{n}^{\circ}$ 2: aplicado para se estimar a carga-limite de Amônia que o Rio Atibaia pode receber sem que sua capacidade de suporte seja violada - CMTD. Para tanto se utilizam os valores de concentração de Amônia estabelecidos segundo a EPA, ver a Tabela 1, e a vazão do Rio Atibaia. A vazão utilizada é a mesma do método $\mathrm{n}^{\circ} 1$. Por exemplo: para uma temperatura da água de $20{ }^{\circ} \mathrm{C}$ e $\mathrm{pH}$ de 7,0 , busca-se na Tabela 1 de ecotoxicidade da Amônia o valor de 4,15 mg/l. De posse desse valor-limite e da vazão de $7,43 \mathrm{~m}^{3} / \mathrm{s}$, calcula-se a CMTD que é de 2664,1 kg/dia de Amônia.

Método n ${ }^{\circ}$ 3: Esse método foi aplicado para se estimar a carga de Amônia proveniente do Ribeirão Anhumas - CP, para tanto, foram utilizados o número de habitantes cujos esgotos são direcionados pela SANASA para esse ribeirão, a carga de DBO gerada em média por habitante e a relação DBO: $\mathrm{NH}_{3}$ presente no esgoto doméstico da cidade de Campinas. Por exemplo: seja uma população de $1 \mathrm{mil} \mathrm{hab.} \mathrm{cujo} \mathrm{esgoto}$ doméstico é lançado num determinado corpo d'água. Usando a carga de $54 \mathrm{~g} \mathrm{DBO/dia.hab.,} \mathrm{chega-se} \mathrm{a} \mathrm{uma}$ carga de $54 \mathrm{~kg} /$ dia lançada diariamente por toda a população. Supondo, por exemplo, que para cada miligrama de DBO lançada por pessoa, também se emite igual quantidade de Amônia, haverá um lançamento de $54 \mathrm{~kg} /$ dia de Amônia. Esse é um método indireto para se obter a carga de Amônia. O recomendável é a medição da concentração de Amônia nas águas do Ribeirão Anhumas e a medição de sua vazão, como foi feito no método $\mathrm{n}^{\mathrm{o}} 1$.

Método $\mathrm{n}^{\circ}$ 4: aplicado para se estimar a carga de Amônia gerada em toda a bacia do Rio Atibaia - CP. Para tanto foram utilizadas a carga total em DBO do esgoto doméstico não-tratado gerado em toda a bacia do Rio Atibaia (CETESB, 2000b), e uma relação DBO: $\mathrm{NH}_{3}$ a exemplo da citada no método $\mathrm{n}^{\circ} 3$. Esse método também é uma forma indireta de obter a carga total de Amônia lançada no Rio Atibaia. Difere do método no 3 apenas quanta a carga de DBO lançada.

\section{RESULTADOS}

\section{Estimativa das carga máxima total diária (CMTD) e carga total diária (CTD) de Amônia no Rio Atibaia}

A Tabela 3 mostra dados de vazão, concentração de Amônia medida, temperatura, $\mathrm{pH}$ e concentração de Amônia segundo os critérios da EPA. Os valores de concentração da Amônia (os critérios ecotoxicológicos) foram retirados da EPA fazendo uso dos valores de $\mathrm{pH}$ e temperatura. Para os monitoramentos de perfis 24 h são mostrados valores médios, máximos e mínimos. Os valores máximos e mínimos foram definidos em função da concentração de Amônia medida.

A Figura 3 mostra as cargas de Amônia, CTD e CMTD, para os três pontos de coleta ao longo do Rio Atibaia. Essas cargas foram estimadas utilizando os métodos $n^{\circ}$. 1 e $n^{\circ} 2$, respectivamente. Analisando os resultados da Figura 3 pode-se observar que a CTD ultrapassou o limite de carga estabelecido pela CMTD somente no ponto P.3, próximo a Paulínia. Esse resultado está coerente com o perfil das fontes emissoras, que segue a densidade urbano-industrial presente na bacia do Rio Atibaia. Essa violação da qualidade das águas em termos de proteção da vida aquática ocorreu na estação seca, justamente o período mais crítico em se tratando de fontes pontuais, pois o poluente tem sua concentração aumentada com a menor vazão dos rios. Quando os resultados se referem ao período das chuvas (principalmente as coletas $\mathrm{B}, \mathrm{E}$, E.1 e E.2, para os pontos P.1, P.2 e P.3) a CMTD se distancia da CTD. Resultado esperado, pois a maior vazão dilui a Amônia lançada na água. Convém lembrar que pela EPA a ecotoxicidade da Amônia é definida pela relação concentração-tempo-frequência. Portanto, os resultados aqui apresentados cobrem $\mathrm{o}$ aspecto concentração apenas. Um monitoramente mais longo poderia retratar melhor a presença poluidora da Amônia nessa bacia hidrográfica.

\section{Estimativa da carga pontual (CP) de Amônia emitida pelo Ribeirão Anhumas}

Após as estimativas da CMTD e da CTD para os três pontos de coleta localizados no Rio Atibaia, partiu-se para as estimativas das cargas emitidas pelas fontes pontuais de Amônia presentes nessa bacia. Para estimar a carga emitida pela fonte pontual Ribeirão Anhumas $\left(\mathrm{CP}_{\text {Anhumas }}\right)$ foi aplicado o método $n^{\circ} 3$. Foram utilizados os seguintes dados: população aproximada cujo esgoto bruto é direcionado para o Ribeirão Anhumas de 250 mil, carga de DBO gerada em média por habitante de $54 \mathrm{~g} /$ dia.hab. e a relação DBO: $\mathrm{NH}_{3}$ de 6,5:1. Essa relação DBO: $\mathrm{NH}_{3}$ foi levantada por Silva (2004) na estação de tratamento de esgoto de Samambaia, 
Tabela 3 - Dados de vazão, concentração de Amônia, temperatura, pH e valor de ecotoxicidade da Amônia segunda a EPA

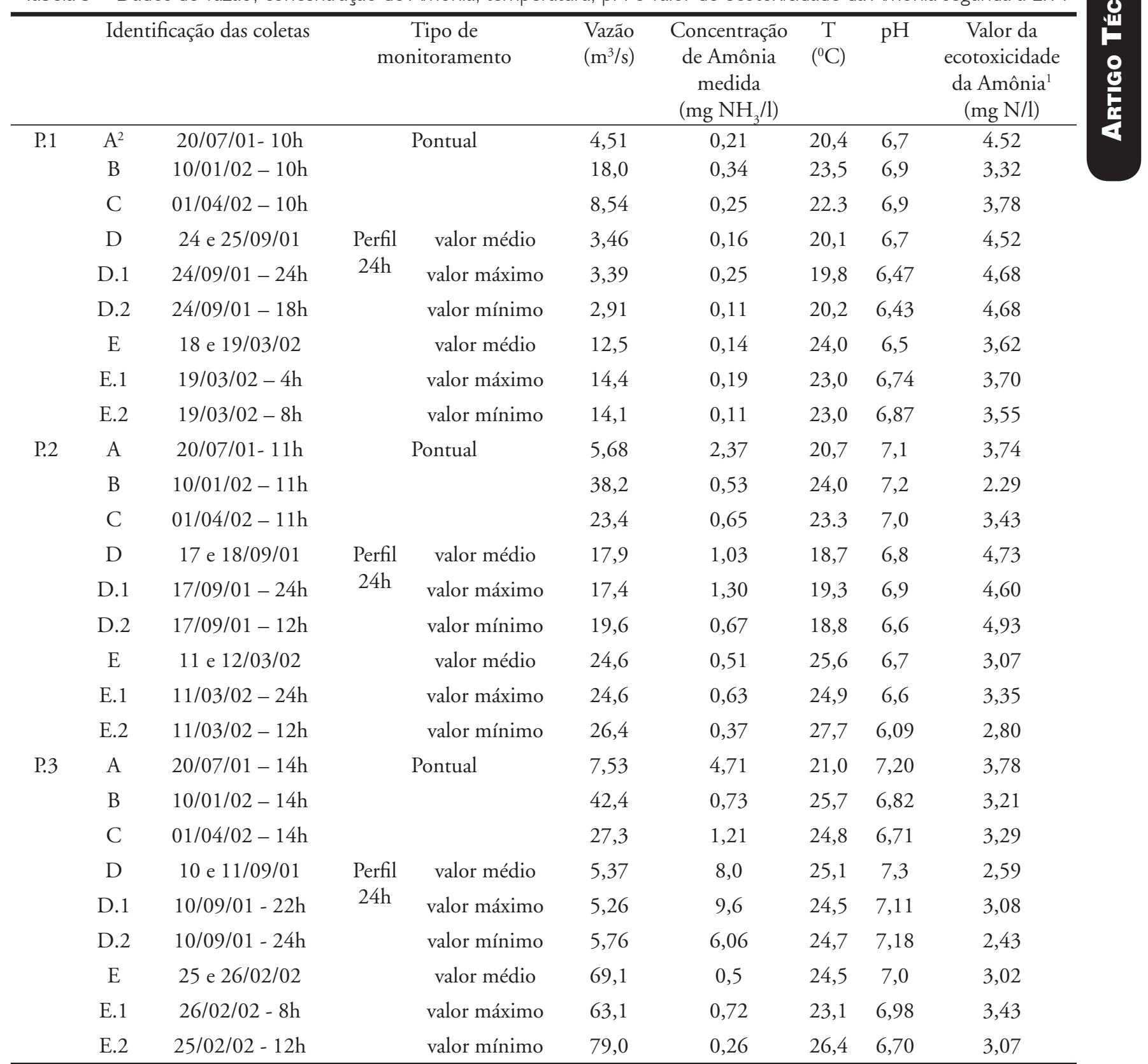

${ }^{1}$ Os valores da ecotoxicidade da Amônia foram retirados da "Update of ambient Water Quality Criteria for Ammonia" (EPA, 1999b). Neste documento a concentração da Amônia está expressa em mg N/l. Para os cálculos da CTD e CMTD fez-se a conversão para mg $\mathrm{NH}_{3} / \mathrm{l}$.

${ }^{2}$ As letras auxiliam na interpretação da Figura 3.

responsável por tratar 5\% do esgoto doméstico de Campinas. É importante esclarecer que a relação obtida DBO: $\mathrm{NH}_{3}$ apresenta a fragilidade de referir-se apenas ao esgoto doméstico bruto tratado pela estação de $\mathrm{Sa}$ mambaia da cidade de Campinas, portanto não considera aspectos como a sazonalidade da composição do esgoto doméstico ou a diversidade qualitativa desse efluente, pois sabe-se que entre outros fatores, os hábitos alimentares influenciam nessa composição. Desse modo, o uso dessa relação DBO: $\mathrm{NH}_{3}$ está susceptível de considerável melhoria e passa a ser utilizada nesse estudo apenas como uma estimativa primeira e superficial da carga doméstica de Amônia do esgoto de Campinas direcionado para o Rio Atibaia através do Ribeirão Anhumas. De posse dos dados, calculou-se a carga de DBO total gerada pelos 250 mil habitantes, $13.500 \mathrm{~kg} / \mathrm{dia}$. Utilizando a relação DBO: $\mathrm{NH}_{3}$ encontrou-se o valor de $2077 \mathrm{~kg}$ de $\mathrm{NH}_{3} /$ dia. Comparando esse valor de carga de Amônia, que o Ribeirão Anhumas lança diariamente no ponto P.3, com as CTD estimadas para o ponto P.3, ver Figura 3, percebe-se que o Ribeirão Anhumas responde por considerável parcela da CTD nesse ponto do Rio Atibaia. Como exemplo, seja o valor da CTD da campanha de 20 de setembro de 2001, ponto P.3 na coleta A da Figura 3. O valor da CTD é próximo a $3000 \mathrm{~kg}$ de Amônia/dia. Pode-se observar que o Ribeirão Anhumas contribui com apro- 


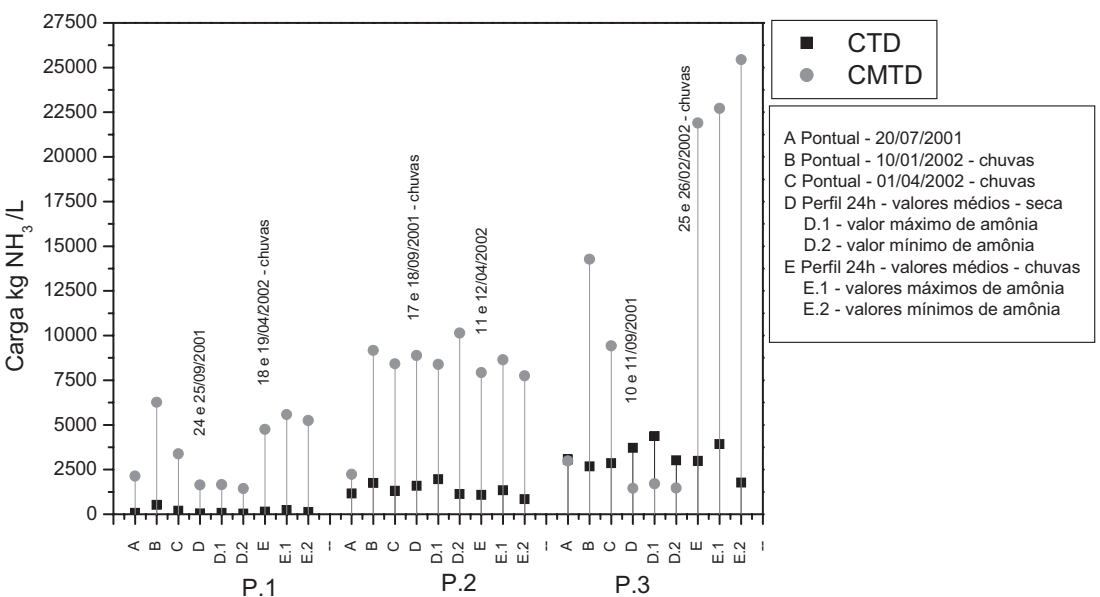

Figura 3 - Estimativas das cargas de Amônia nos pontos de coleta de água ao longo do Rio Atibaia em diferentes campanhas, cobrindo o período de seca e de chuvas. São mostradas as CTD, calculadas a partir de dados de vazão e concentração de Amônia medida, e as CMTD, calculada em função da vazão e da concentração de Amônia definidas pela EPA, utilizando as variáveis $\mathrm{T}$ e $\mathrm{pH}$

ximadamente $70 \%$ da carga de Amônia encontrada nesse ponto, confirmando a Amônia como um poluente predominantemente de origem doméstica.

\section{Estimativa da carga pontual (CP) de amônia emitida em toda a bacia do Rio Atibaia}

Finalmente, foi realizada a estimativa da carga de Amônia proveniente de todo o esgoto doméstico não-tratado da bacia do Rio Atibaia $\left(\mathrm{CP}_{\text {Atibaia }}\right)$. Para essa estimativa foi utilizado o método $\mathrm{n}^{\circ} .4$. A carga de DBO do esgoto doméstico não-tratado gerado em toda a bacia do Rio Atibaia é de $30.341,11 \mathrm{~kg} / \mathrm{dia}$ (CETESB, 2000b). Aplicando-se a relação DBO: $\mathrm{NH}_{3}$ de 6,5:1 obtém-se uma carga de Amônia de $4668 \mathrm{~kg}$ de $\mathrm{NH}_{3} /$ dia. Esse valor dá uma idéia da grandeza da carga de Amônia presente nessa bacia com origem no esgoto doméstico não-tratado.

\section{Estimativas das cargas de amônia (CTD e CMTD) na bacia do Rio Atibaia utilizando dados dos relatórios da águas interiores da CETESB}

Este estudo aplicou o método da CMTD aos dados de monitoramento contidos nos "Relatórios de Qualidade das Águas Interiores do Estado de São Paulo" para os anos de 2000 a 2004 (CETESB, 2000a a 2004). Para as es- timativas foram utilizados os dados de Amônia (nitrogênio amoniacal total), $\mathrm{pH}$, temperatura e vazão disponíveis nesses relatórios. A Tabela 4 mostra os dados das CTD e CMTD para os anos de 2000 a 2004.

Para o ponto P.1, a Tabela 4 mostra valores da CTD de 7 a 68 vezes menores que os da CMTD. Para os pontos P.2, a Tabela 4 mostra dados de CTD de 2 a 10 vezes menores que a CMTD, indicando um maior aporte de Amônia na medida em que se avança na bacia do Rio Atibaia. Para o ponto P.3, os valores mostrados na Tabela 4 indicam diferenças de 0,7 a 6 vezes entre as CTD $\mathrm{e}$ as CMTD. A violação da capacidade de suporte das águas do Rio Atibaia foi observada apenas no ponto P.3, Paulínia, para os anos de 2001 a 2004.

Outra dimensão que o método da CMTD permite explorar é a realocação de investimentos em uma bacia hidrográfica via aquisição de cotas de emissão de carga de Amônia. No Rio Atibaia existem empreendimentos emissores de Amônia além do esgoto doméstico. Certamente pelo desenvolvimento da região, novas licenças de emissão desse poluente devem ser solicitadas. Deste modo, as empresas emissoras de Amônia poderiam adquirir cotas de emissão de carga desse poluente por meio da realização de investimentos em estação de tratamento de esgoto, por exemplo. Uma situação interessante ocorre com o Ribeirão Pinheiros, que recebe esgoto não-tratado das cidades de Campinas, Vinhedo e Valinhos, situação existente à época em que esse estudo foi realizado. A SANASA, empresa de água e esgoto de Campinas, capta água do Rio Atibaia logo abaixo da afluência do Ribeirão Pinheiros (ver Figura 1), arcando com consideráveis custos para o tratamento dessa água. Os empreendimentos emissores de Amônia poderiam concentrar investimentos numa ETE que melhorasse a qualidade das águas do Ribeirão Pinheiros, de modo a refletir diretamente nos custos de tratamento de água da Sanasa. O efeito desse investimento poderia ser mais estratégico que investimentos isolados, pois segundo Bastiaan et al (2003) o custo de tratamento de água de um manancial com padrões de qualidade classe 2 custa $\mathrm{R} \$ 0,58 / \mathrm{m}^{3}$, enquanto essa captação em manancial com padróes classe 3 chega a $R \$ 1,65 / \mathrm{m}^{3}$. Segundo esses autores, numa cidade de 60 mil habitantes a economia anual pode girar em torno de 7 milhōes de reais, recurso capaz de implantar uma ETE para essa cidade. O Ribeirão Anhumas também está susceptível a esse tipo de investimento, melhorando a qualidade das águas do Rio Atibaia a jusante para abastecimento público e devolvendo à Represa de Americana a possibilidade de recuperação de seu valor paisagístico, recreacional e como local de proteção para uma enorme biodiversidade. Infelizmente, o presente estudo não avança na elaboração dessa engenharia econômico-ambiental, porém sinaliza para essa sinergia entre monitoramento/controle das emissōes indústrias, licenciamento ambiental e açôes gerenciais e de investimentos numa bacia hidrográfica.

\section{CONCLUSÃO}

A aplicação do método da carga máxima total diária (CMTD) à Amônia no Rio Atibaia mostrou-se uma ferramenta útil no gerenciamento da qualidade das águas desse rio, relacionando a qualidade das águas às fontes emissoras presentes na bacia. $\mathrm{O}$ método da CMTD revelou uma situação mais crítica no ponto de monitoramento P.3 da bacia, trecho próximo à foz do Rio Atibaia. Nesse ponto, a capacidade de suporte do Rio Atibaia para manter a vida aquática foi ultrapassada algumas vezes no decorrer dos anos de 2001 a 2004. O esgoto doméstico não-tratado, através do Ribeirão Anhumas, por sua vez, foi identificado como a principal fonte de Amônia, respondendo pela maior parte da carga lançada no Rio 
Tabela 4 - Comparação das CTD e CMTD',2,3

\begin{tabular}{|c|c|c|c|c|c|c|c|c|}
\hline Ponto & Ano & $\begin{array}{c}\text { Carga } \\
\left(\mathrm{kg} \mathrm{NH}_{3} / \text { dia }\right)\end{array}$ & Jan & Mar & Mai & Jul & Set & Nov \\
\hline \multirow[t]{10}{*}{ P.1 } & 2000 & CTD & 243,8 & 36,5 & 131,4 & 175,2 & 92,6 & 307,9 \\
\hline & & CMTD & 4603,9 & 4714,6 & 3780,7 & 3399,9 & 4677,4 & 6466,5 \\
\hline & 2001 & CTD & 570,2 & 384,3 & 241,7 & 73,7 & 148,6 & 46,7 \\
\hline & & CMTD & 2623,1 & 3053,7 & 3295,3 & 3795,5 & 1843,7 & 2561,4 \\
\hline & 2002 & CTD & 230,9 & 66,0 & 139,8 & 38,6 & 1345,2 & 69,5 \\
\hline & & CMTD & 1526,0 & 3709,7 & 2614,2 & 3977,9 & 1937,2 & 2167,3 \\
\hline & 2003 & CTD & 353,4 & 459,0 & 120,6 & 191,3 & 28,4 & 101,8 \\
\hline & & CMTD & 4345,7 & 2204,4 & 1656,4 & 4052,5 & 665,2 & 2188,3 \\
\hline & 2004 & CTD & 60,6 & 106,4 & 97,4 & 107,0 & 288,4 & 493,3 \\
\hline & & CMTD & 1291,2 & 1990,3 & 2138,9 & 3832,4 & 2302,0 & 3088,3 \\
\hline \multirow[t]{10}{*}{ P. 2} & 2000 & CTD & 2336,9 & 1108,6 & 629,4 & 1145,7 & 1691,8 & 3468,0 \\
\hline & & CMTD & 10158,6 & 8916,0 & 4446,1 & 4159,6 & 10123,1 & 10949,6 \\
\hline & 2001 & CTD & 802,0 & 1747,3 & 1204,4 & 1258,0 & 1057,5 & 1410,0 \\
\hline & & CMTD & 5284,7 & 7654,7 & 6284,2 & 4567,4 & 1524,6 & 2031,4 \\
\hline & 2002 & CTD & 1351,0 & 1578,8 & 685,6 & 1137,6 & 778,2 & 682,0 \\
\hline & & CMTD & 3331,8 & 10330,1 & 4799,1 & 4762,5 & 4454,7 & 2619,3 \\
\hline & 2003 & CTD & 926,9 & 1045,9 & 550,4 & 803,2 & 294,0 & 592,0 \\
\hline & & CMTD & 10620,7 & 4304,4 & 1585,1 & 5391,3 & 1763,9 & 2277,1 \\
\hline & 2004 & CTD & 2857,9 & 469,3 & 275,2 & 1104,4 & 321,7 & 448,9 \\
\hline & & CMTD & 3816,0 & 2892,5 & 4321,4 & 9692,2 & 2226,9 & 1531,4 \\
\hline \multirow[t]{10}{*}{ P.3 } & 2000 & CTD & 2933,9 & 4290,4 & 3326,4 & 5007,7 & 1472,3 & 1477,4 \\
\hline & & CMTD & 9872,8 & 9526,6 & 4011,6 & 2928,4 & 3545,7 & 4077,7 \\
\hline & 2001 & CTD & 3732,1 & 2981,4 & 2904,0 & 3472,6 & $\underline{816,3}$ & $\underline{4398,1}$ \\
\hline & & CMTD & 8406,0 & 6559,1 & 5425,9 & 4232,2 & 2642,8 & 3133,7 \\
\hline & 2002 & CTD & 1449,7 & 2098,1 & 2364,8 & 1555,2 & 1815,7 & 2370,0 \\
\hline & & CMTD & 3799,3 & 9764,4 & 3839,3 & 3227,0 & 2614,6 & 1567,8 \\
\hline & 2003 & CTD & 1091,0 & 2811,3 & $\underline{2822,2}$ & . & . & . \\
\hline & & CMTD & 14757,3 & 7207,1 & 2622,3 & & & \\
\hline & 2004 & CTD & 1421,8 & 2200,3 & 2127,5 & 1013,9 & 2589,4 & . \\
\hline & & CMTD & 3321,8 & 3309,0 & 4161,9 & 6870,0 & 1795,3 & . \\
\hline
\end{tabular}

${ }^{1}$ Os valores de vazão presentes nos relatórios da CETESB (2000a a 2004) são médias diárias. Quando esses valores não estavam disponíveis nos relatórios foram utilizadas médias mensais.

${ }^{2}$ Os valores sublinhados para o ponto P.3 indicam uma violação da capacidade de suporte do Rio Atibaia.

${ }^{3}$ Para a estimativa das CTD foi utilizado o método n.1. Para a estimativa da CMTD foi utilizado o método no 2.

Atibaia, graças à contribuição da cidade de Campinas. Nesse sentido, um resultado prático da CMTD é apontar para a necessidade de estaçôes de tratamento de esgoto em toda a bacia do Rio Atibaia. Pois apesar do grande parque industrial presente nessa região, o esgoto doméstico não-tratado se mostrou a grande fonte de Amônia e consequentemente uma considerável ameaça à vida aquática.

\section{REFERÊNCIAS}

BASTIAAN, P. R.; et al. Tratamento de esgoto e seu efeito no custo agregado de tratamento de água: uma abordagem quantitativa. Projeto Água. NEA. Instituto de Economia, Unicamp. Campinas. SP. 2003.

BRASIL. Ministério do Meio Ambiente. Gerenciamento de Bacias Hidrográficas. Brasília, DF. 1995.

CANADIANENVIRONMENTALASSESSMENT AGENCY. Priority Substances List - Assessment Report
- Ammonia in The Aquatic Environment-May 2000. Canadá. 2000.

CETESB - COMPANHIA DE TECNOLOGIA DE SANEAMENTO AMBIENTAL . Relatório de Qualidade de Aguas Interiores do Estado de São Paulo. Séries Relatórios. São Paulo. 2000(a) a 2004.

CETESB - COMPANHIA DE TECNOLOGIA E SANEAMENTO AMBIENTAL. Projeto Watershed Management 2000 - Brasil/Canadá, (2000). São Paulo. 2000(b). 
CONAMA. CONSELHO NACIONAL DE

JiI MEIO AMBIENTE. Resolução Federal n. 357 de 17 de março de 2005. Disponível em: <http:// www.mma.gov.br> Acesso em: 31 de janeiro de 2006.

CTH-USP. Centro de Tecnologia Hidráulica da USP. São Paulo, 2001.

CWA, 1972. Clean Water Act of United Stated of América. Disponível em: <http://www.epa.gov> Acesso em: 02 de fevereiro de 2006.

EPA - United States Environmental Protection Agency. Protocol for Developing Nutrient TMDLs, EPA 841-B-99-007. 1999(a).

EPA - United States Environmental Protection Agency. 1999 Update of ambient Water Quality Criteria for Ammonia. 822-R-99-014. 1999(b).

EPA - United States Environmental Protection Agency. Notice of Intent To Re-Evaluate the Aquatic Life Ambient Water Quality Criteria for Ammonia. Disponível em: <http://www.epa.gov/waterscien$\mathrm{ce} /$ criteria/ammonia/re-eval-fs.htm $>$ Acesso em: julho de 2005.

FARIA, L. C. \& PASQUINI, C. Flow-injection determination of inorganic forms of nitrogen by gás diffusion and conductimetry, Anal. Chim. Acta, v. 245, p.183-190, 1991.

RELATÓRIO ZERO. Relatório de Situação dos Recursos Hidricos das Bacias Hidrográficas dos Rios Piracicaba, Capivari e Jundiaí. Comitê das Bacias Hídricas dos Rios Piracicaba, Capivari e Jundiaí - CB PCJ. Piracicaba, SP. 2000.

SANASA. Sociedade de Abastecimento de Agua e Saneamento SA. In: Sanasa Hoje. Disponível em: <http://sanasa.com.br> Acesso em: 02 de fevereiro de 2006.

SILVA, G. S. Avaliação do estado de degradação e capacidade de suporte da bacia do Rio Atibaia - região de Campinas/Paulínia - SP. Tese de Doutorado - Instituto de Química, Universidade Estadual de Campinas, Campinas, SP, 2004.

SILVA, G. S. \& JARDIM, W. F. Um novo indice de qualidade das águas para proteção da vida aquática aplicado ao Rio Atibaia, regiāo de Campinas/Paulinia-SP, Quim. Nova, v. 29, n. 4, p. 689-694, 2006.

\section{Endereço para correspondência:}

Gilberto Silvério da Silva

Av. Brasil 4232,

C.P 271 ,

85884-000 Medianeira - PR -

Brasil

Tel.: (45) 3240-8000

Fax: (45) 3240-810I

E-mail: gilberto@utfpr.edu.br 